\title{
Kawa Modeli'nin Kullanımına İlişkin Olumlu ve Olumsuz Özelliklerin İncelenmesi
}

Investigation of the Positive and Negative Characteristics in Using the Kawa Model

Damla AYGÜN ${ }^{1}$, Burcu Semin AKEL ${ }^{2}$

${ }^{1}$ Erg., Hacettepe Üniversitesi, Sağlık Bilimleri Fakültesi, Ergoterapi Bölümü, Ankara

${ }^{2}$ Doç.Dr., Hacettepe Üniversitesi, Sağlık Bilimleri Fakültesi, Ergoterapi Bölümü, Ankara

\section{öz}

\begin{abstract}
Amaç: Ergoterapi modelleri çoğunlukla Batılı terapistler tarafından geliştirilmesi, Batı kültür normlarına uygun olması ve bu nedenle de Asya, Afrika ve Doğu ülkelerindeki hastaların şartları için her zaman geçerli olmaması nedeniyle eleştirilmektedir. Modellerin klinik ve kültürel açıdan uygunluğunun, gelişmekte olan ülkelerde araştıııması önerilmektedir. Bu çalışmanın amacı Doğu felsefesine göre geliştirilen Kawa Modeli'nin uygulama sırasında olumlu ve olumsuz özelliklerini incelemektir. Gereç ve Yöntem: Araştırma nitel desende oluşturuldu ve yürütüldü. Çalışmaya Hacettepe Üniversitesi'nde staj yapmakta olan 20 son sınıf ergoterapi öğrencisi katıldı. Her katıııcı tarafından birer hasta Kawa Modeli kullanılarak incelendi. Katılımcıların modeli kullanma ile ilgili deneyimlerini değerlendirmek için katıımcılarla yarı yapılandııımış görüşsme yapıldı. Görüşme sonuçları analiz edildi. Sonuçlar: Modelin olumlu özellikleri kişiyi detaylı olarak analiz etmesi ve müdahale planına yardımcı olması idi. Olumsuz özellikler olarak modeli hastalara açıklamanın zorluğu, ergoterapi öğrencilerinin yeterli deneyime sahip olmamaları ve modelin yapısı olarak ortaya konuldu. Tartışma: Katıımcıların modeli uygulamaya karşı ön yargı ve güvensizliklerinin olması çalışma için bir limitasyon oluşturdu. Olumlu özellikler göz önüne alındığında modelin pratikte kullanımının teşvik edilmesi önerilmektedir.
\end{abstract}

Anahtar Kelimeler: Kawa Modeli; Nitel araştırma; Eğitim; Ergoterapi; Teorik modeller

\section{ABSTRACT}

Purpose: The occupational therapy models are often criticized for being mostly developed by Western Therapists, being in compliance with Western cultural norms, unsuitability for clients in Asia, Africa and Western countries. The clinical and cultural utility of the models are advised to be explored in developing countries. The purpose of this study is to examine the positive and negative features while using the Kawa Model. Material and Methods: The study was designed and conducted in qualitative design. A total of 20 senior class occupational therapy students at Hacettepe University participated to the study. One client was examined by each participant using the Kawa Model. Semi-structured interview was done to analyze experiences while using the Kawa Model. Data collected from interview was analyzed. Results: Positive features of the model were analyzing the person in detail and guiding the intervention plan. Negative traits were presented as the lack of experience, the difficulty of explaining the model and the structure of the model. Discussion: Participants' prejudices and insecurities against implementing the model constituted a limitation for the study. It is suggested that studies should be carried out to encourage the use of the model in practice.

Key Words: The Kawa Model; Qualitative research; Education; Occupational therapy; Theoretical models 
Kuramsal modeller yapılandırılmış bir şekilde, kişinin zorluklarını belirlemek, müdahaleyi şekillendirmek ve kişinin gelişimini değerlendirmek için kullanıır. Aynı zamanda, evrensel olarak uygulanan rehabilitasyon süreci için yönergeler de sağlar (Duncan, 2006). Kuramsal modellerin pratikte uygulanması basit bir formül üzerine kurulu değildir. Bunun yerine pratikte uygulamak için modeli ve uygulamasını kapsamlı olarak görebilecek bir anlayışa intiyaç vardır (Duncan, 2006; Davies, 2006).

Ergoterapi modelleri genellikle Batılı terapistler tarafından geliştirilmiştir. Bu modeller Asya, Afrika ve Doğu ülkelerindeki hastaların şartları için her zaman geçerli olmaması nedeniyle kültürel uygunsuzluk bakımından literatürde eleştirilmektedir (Iwama, 2005b; Iwama, 2003). Kültürel çeşitliliğin anlamı ve önemi ergoterapistlerin kültürel açıdan yetkin bir şekilde uygulama yapabilmeleri için esastır (Iwama, Thomson, Macdonald, 2009). Batı merkezli modeller aktiviteyi; kişinin aktif ve üretken olması, çevresinde üstünlük kurması ve bireyselliği için iç motivasyonları ve intiyaçları olarak görmektedir (Kantartzis, Molineux, 2011). Bu bakış açısı bireyselliğe, iç motivasyona, özerkliğe, bağımsızlığa ve çevre üzerindeki üstünlüğe değer veren batı toplumlarına uyum göstermektedir. Doğu toplumları ise, kişiyi çevresiyle bir arada görebilir, bireysellik yerine kolektivizme, bağımsızlık yerine dayanışmaya önem verir (Iwama ve ark, 2009; Hammell, 2009). Bu nedenle Batı merkezli modellerin, kolektivizmi içeren, sorumluluğun paylaşıldığı, çevreyle iç içe bulunan doğu toplumlarına uygulanması zor olduğu için aktivitenin özünü yakalamada başarısız olduğu öne sürülmektedir (Iwama ve ark, 2009; Hocking, Pierce, Shordike ve ark, 2008).

Kawa (Japon Nehri) Modeli batı kültürüne karşı önemli ve yeni bir alternatif sunan kuramsal bir modeldir (Iwama ve ark, 2009; Turpin, Nelson, 2007). Model kişinin hayatını bir nehir olarak tasvir etmesi temeline dayanır. Nehir kişinin doğumundan hayatının sonuna kadar olan yolculuğu temsil eder. Nehrin içindeki su; kişinin hayat akışını, kayalar; engeller ve zorlukları, odun parçaları; kişisel özellikleri, nehrin tabanı ve duvarları; kişinin çevresini yansıtır. Ayrıca nehrin içindeki boşluklar ergoterapi müdahalesinin odaklanması gereken alanlardır (Iwama, 2006).

Literatüre bakıldığında Kanada Aktivite Performans Modeli (CMOP), İnsan Aktivite Modeli $(\mathrm{MOHO})$ ve Kişi-Çevre-Aktivite Modeli (PEO) batı ülkelerinde en yaygın olarak öğretilen ve kullanılan modellerdir (Ashby, Chandler, 2010). Ancak ergoterapi mesleği başlangııından bu yana değişmiş ve gelişmiştir. Batılı bakış açısından ziyade kültürel olarak daha dengeli bir anlayışa odaklanmaya başlamıştır (Gillen, Greber, 2014). Bu nedenle bireyleri kendi kültürü içerisinde ele almaya imkan tanıyan Kawa Modeli'nin farklı kültürlerde ve gruplarda etkinliğini inceleyen çalışmalar gerçekleştirilmiştir (Tripathi, Sweetman, Zapf ve ark. 2017; Lape, Scaife, 2017; Nelson, 2007). Ancak modelin klinikteki etkinliği ve ergoterapistlerin modeli kullanma deneyimi üzerine yayınlanmış çok az sayıda araştırma vardır (Paxson, Winston, Tobey ve ark, 2012). Türkiye'de yapılan çalışmalarda ise ağırlıklı olarak CMOP (Öz, Akı, 2016; Salar, Günal, Pekçetin ve ark, 2016), MOHO (Salar, 2018; Kashefimehr, 2014) ve PEO (Batıhan, Kayıhan, 2016; Şen, Öksüz, 2016) modellerinin kullanıldığı görülür ve Kawa Modeliyle ilgili yapılan herhangi bir çalışma yer almamaktadır. Kawa Modeli'nin doğu felsefesi ile Türk gelenek ve göreneklerinin benzer özellikler göstermesi bakımından Türk kültürü içerisinde kullanımı incelenmek istenmiştir. Bu nedenle çalışmanın amacı Kawa Modeli'nin uygulanma sırasinda olumlu ve olumsuz özelliklerinin ergoterapi öğrencilerinin gözünden incelenmesidir.

\section{GEREÇ VE YÖNTEM}

Araştırma nitel desende oluşturuldu ve yürütüldü. Çalışma 01/02/2017 - 30/04/2017 tarihleri arasında, Hacettepe Üniversitesi Sağlık Bilimleri Fakültesi Ergoterapi Bölümü'nde staj gören ve erişkin hastalarla çalışan son sınıf öğrencileri ile gerçekleştirildi. Mezun olarak sahada çalışan az sayıda ergoterapist olduğu için çalışmanın son sınıf öğrencileriyle gerçekleştirilmesi uygun görüldü. Katılım gönüllülük esasına ve akran ilişkisine dayalı olup toplam 20 öğrenci katılmayı kabul etti. Her katııımc tarafından birer hasta Kawa Modeli kullanılarak incelendi. Öğrencilerin staj dönemleri sonunda, yarı yapılandırılmış nitel görüşme yöntemi kullanılarak veri toplandı.

\section{Veri Toplama Aracının Geliştirilmesi}

Veri toplama aracı olarak yarı yapılandırıımış görüşme formu kullanıldı. Soruların her biri farkı verileri elde etmek üzere hazırlandı. Görüşme soruları literatür taraması ışığında oluşturuldu. Bu görüşmeler ortalama 30 dakika sürdü. Görüşme formunda yer alan ve katılımcılara yöneltilen sorular şu şekildedir:

Hastanıza modeli açıklamakta zorlandınız mı? Evet ise modelin hangi kısmını açıklamakta zorlandınız? 
Modeli uygulamakta zorlandınız mı? Evet ise buna neden olan faktörleri açıklayınız.

Modelin kişiyi ayrıntılı ve kapsamlı bir şekilde analiz ettiğini düşünüyor musunuz?

Model uygulamada size kolaylıklar sağladı mı? Sağladıysa hangi açıdan bir kolaylık sağladığını düşünüyorsunuz?

Modelin rehabilitasyon sürecini kolaylaştırdığını düşünüyor musunuz?

Modelin müdahale planını oluşturmada yardımcı olduğunu düşünüyor musunuz? Evet ise hangi açıdan yardımcı oldu?

Diğer modellerle karşılaştırıldığında daha avantajlı olduğu bir durum var mı?

\section{Verilerin Analizi}

Katılımcılar ile yapılan görüşmeler ses kayıt cihazı kullanılarak kaydedildi. Kaydedilen veriler bilgisayar ortamında Word belgesi haline getirildi ve nitel araştırma tekniklerden içerik analizi kullanılarak çözümlendi. Bu çözümleme işleminde sırasıyla; kodlama, temaların (kategorilerin) bulunması, verilerin kodlara ve temalara göre organize edilmesi ve tanımlanma ile bulguları yorumlama işlemleri yapıldı. Ayrıca her soruya verilen birkaç cevap da aynen sunulma yoluna gidildi.

\section{SONUÇLAR}

Çalışmaya hepsi son sınıf ergoterapi öğrencilerinden oluşan 20 kişi katıldı. Çalışmada öğrenciler tarafından 10'u erkek, 10'u kadın olmak üzere toplam 20 birey Kawa Modeli'ne göre incelendi. Bu bireylerin yaşları 21 ile 71 yıl arasında olup, ortalama yaşları 40,35 yıl olarak bulundu. Katılımcıların çalışmada incelediği bireylerin 4'ü Bipolar Affektif Bozukluk, 3'ü Depresyon, 2'si Şizofreni tanısına sahipti. Diğer bireylerin ise Nörofibromatozis, Crush Sendromu, Medial Epikondilit, Mallet Finger, Multiple Skleroz, Lumbal Disk Hernisi, Bulimiya Nervoza, Stroke, Fokal Distoni, Arnold Chiari, Romataid Artrit gibi farklı tanılara sahip olduğu görüldü.

Nitel araştırma sonuçlarına göre Kawa Modeli'nin kullanımına yönelik olumlu ve olumsuz özellikler belirlendi. Olumsuz özellikler için veriler analiz edildiğinde 3 temel kod dikkat çekmektedir; modelin açıklanması, deneyim ve modelin yapısı.

\section{Modelin açıklanması}

Katılımcıların \%55'i (11) bireylere modeli açıklamada zorlandıklarını ifade etti. \%54,5'i (6) bu zorluğun nedeni olarak metafor kullanımını gösterdi. \%27,2'si (3) modelin amacını ve neden uyguladıklarını açıklamada, \%27,2'si (3) ise hastadan modelin anlaşıldığına dair geri bildirim alma konusunda zorlandıklarını belirtti. Katılımcılar modeli açıklamadaki zorlukları şu şekilde ifade ettiler:

"Kişiye 'Hayatınızı bir nehir olarak düşünün, kayalar da sizin engelleriniz...' şeklinde anlatmaya başladığımda bu metaforları anlamakta zorlandı. Bu nedenle tekrar tekrar anlatmam gerekti" (EC).

"Kişinin modeli anlayıp anlamadığından emin olamadığım için tekrar anlatmak zorunda kaldım” (BK).

\section{Deneyim}

Katılımcıların \%35'i (7) modele ilişkin deneyimlerinin az olmasından dolayı modeli bireylere açıklamada ve modeli uygulamada zorlandıklarını ifade etti. \%71,4'ü (5) bunun nedeni olarak modeli klinikte kullanmadıklarını ve pratik deneyimleri olmadığını gösterirken, \%28,6'sı (2) ise modelin kültürümüze yabancı olduğunu belirtti.

"Modeli derste öğrendik ama hasta üzerinde uygulama şansımız hiç olmamıştı. Stajlarda da genellikle kullanmadığımız bir model olduğu için çok iyi bilmiyoruz" (BÖ).

"Modeli ilk defa bir hastada uyguladım ve yeteri kadar tecrübem olmadığı için süreci çok iyi organize edemedim, kişiyi doğru bir şekilde yönlendiremedim" (GG).

"Kişi daha önce hiçbir profesyonelle bu şekilde bir çalışma yapmadığını ve böyle bir iletişim kurmadığını söyledi. Bu nedenle onun için biraz yabancı ve zorlayıcı oldu" (ZE).

\section{Modelin yapısı}

Katılımcıların \%50'si (10) bireylerin modeli uygularken çizim konusunda tereddüt yaşadıklarını ve metaforların birbirinden farkını ayırt etmede zorlandıklarını ifade etti. Katılımcıların \%30'u (6) modelin, bireyleri psikososyal performans alanlarında incelemede başarılı olduğunu fakat duyu-motor performans alanlarını incelemede yetersiz olduğunu ifade etti. Modelin yapısıyla ile ilgili katılımcıların\%20'si (4) tarafından eleştirilen bir başka özellik de modelin her hasta için uygun olmadığı yönünde idi. Özellikle modelin etkin bir şekilde uygulanması için bireylerin kognitif olarak yeterli bir düzeyde olmaları gerektiği aksi takdirde modelin kullanımının zor olacağını vurguladılar.

"Modeli uygularken kişi odun parçaları ve kayaları birbirinden ayırmakta zorluk yaşadı. Bu nedenle birlikte tekrar üzerinden geçmemiz gerekti” (ÇA). 
"Modelde kişinin güçlü yönlerini, kişisel özelliklerini ve problemlerini sorguluyoruz ama bunlar bizi daha çok psikososyal bir bakış açısına götürüyor. Hastanın motor bir problemi var ve bu yüzden tedaviye geliyor. Ama modeli uygularken kişinin motor problemiyle ilgili olan düşüncelerine ulaşamadım" (YF).

"Kişi, kognitif ve emosyonel durumundan ötürü kendini açmada ve bu tarz kendini yansıtıcı etkinliklere katılmada zorlanan bir hastaydı" (ET).

Modelin kullanımına ilişkin olumlu özellikler için veriler analiz edildiğinde 3 temel kodun dikkat çektiği görülmektedir; kişiyi tanıma, müdahale planı çizme ve modelin yapısal özellikleri

Kişiyi tanıma

Katılımcıların \%55’i (11) modelin kişiyi ayrıntılı olarak incelediğini ve tanımaya yardımcı olduğunu ifade etti. \%50'si (10) kişinin kendini tanımasına yardımcı olduğunu ve buna ek olarak kişinin kendisiyle ilgili iç görüsünü yansıttığını, kişiyi kendi gözünden incelemeye olanak sağladığını belirtti. \%35'i (7) ise modelin kişinin ilgi, beceri ve motivasyonlarını tanımladığını dile getirdi. Ayrıca katııımılar model sırasında kişinin kendini ifade etmesinin kolaylaştığını ve hasta terapist arasındaki iletişimin güçlendiğinden bahsettiler.

"Hastam bana daha önce anlatmadıklarını model sırasında anlattı. Kişiyi tanımam ve aramızdaki iletişimin gelişmesi açısından bana çok büyük bir yararı oldu" (BM).

"Kişi model sırasında kendisinin olumlu ve olumsuz yönlerini görebiliyor. Aslında bir modelden daha çok, kendini yansıtma ve tanıma için güzel bir çalışma" $(E Y)$.

"Bu modeli uyguladıktan sonra hastamın bana karşı olan bakış açısı çok değişti. Eskiden beni gördüğünde yolunu değiştiriyordu ve benimle hiçbir aktiviteyi yapmak istemiyordu. Ama birlikte modeli uyguladıktan sonra bir yakınlık kurduk ve bana kendisini açtı" (ET).

Müdahale planı çizme

Katılımcıların \%60'ı (12) bireylerin problem alanlarını ve önceliklerini belirlemede modelin yardımcı olduğunu, kişinin beceri ve motivasyonlarını belirleyerek müdahale planında yol gösterici olduğunu düşünmekte idi. \%25'i (5) modelin kişinin kendini tanımasına olanak sağladığından ötürü hastalar için terapötik bir yararı olduğunu belirtti. Katılımcıların \%15'i (3) ise modelin psikiyatrik hastalarda kullanımının etkili olduğunu vurguladı.
"Modelde kişinin nehrini, kayalarını ve odun parçalarını birlikte incelediğimiz için kişinin hayatındaki engellere ve problemlere ulaşmada çok daha etkili bir model. Müdahale planında neyin öncelikli olduğuna aktif bir şekilde kişiyle birlikte karar vermiş oluyoruz" (CB).

"Psikiyatrik problemi olan bireylerin kendilerini sözel olarak ifade etmede zorlandıklarını biliyorum. Ama kişiden kendi nehrini çizmesini istediğimde daha iyi şeyler ortaya çıkardığını gördüm. Bence psikiyatrik hasta grubunda bu model kesinlikle kullanılmalı" (EY).

"Model, kişinin ilgi ve motivasyonlarını bize gösterdiği için kişinin tedaviye aktif katıımını sağlamada yardımcı olduğunu düşünüyorum" (AE).

Modelin yapısal özellikleri

Katıımcıların \%60'ı (12) modelin yapısal özelliklerini, kişi ve terapist açısından olumlu olarak niteledi ve uygulamada birtakım kolaylıklar sağladığını belirtti. \%41,6'sı (5) bu kolaylığın modelin görsel bir model olmasından kaynaklandığını ifade ederken, 33,3'ü (4) modelin kolay ve sistematik bir model olduğunu, $\% 25$ 'i (3) ise modelin kişideki mevcut gelişimi göstermede yardımcı olduğunu dile getirdi.

"Modelin görsel olması, pratiğe dayanması ve sonunda kişiyle birlikte bir ürün ortaya çıkarılması modelin güçlü yanlarını oluşturuyor" (BM).

"Kişi kendi hayatını kağıt üzerinde sistemli bir şekilde şematize etmiş oluyor. Bu da diğer modellerde görmeye alışkın olmadığımız bir durum" (BY).

"Kişinin müdahale öncesi ve sonrasındaki mevcut değişimi kişiye gösterildiğinde hem kişinin hem de bizim motivasyonumuz artmış oluyor" (BY).

\section{TARTISMA}

Çalışmadan elde edilen bulgulara göre Kawa Modeli'nin olumsuz özellikleri; modelin açıklanması, deneyim, modelin yapısı; olumlu özellikleri ise kişiyi tanıma, müdahale planı oluşturma ve modelin yapısal özellikleri olarak saptandı.

Carmody ve arkadaşları (2007) tarafından yapılan bir çalışmada Kawa Modeli'nin kişi merkezli olduğu ve bireyleri kendi hayat bağlamları içinde incelemeye olanak sağladığı belirtilmektedir. Bu bağlamların bireylerin katılım düzeylerini etkilemesinden dolayı ergoterapistler için önemli olduğu düşünülmektedir (Baum, Law, 1997). Çalışmamıza katılan öğrencilerin \%30'u (6) Kawa Modeli'nin bireyleri psikososyal performans alanlarında incelemede başarıı olduğunu fakat 
duyu-motor performans alanlarını incelemede yetersiz olduğunu düşünmektedir. Ayrıca katılımcılar modelin 'kişi'yi detaylı olarak inceleme ve analiz etmede başarılı olduğunu fakat ergoterapinin temeli olan 'çevre' ve 'aktivite'yi incelemede yetersiz olduğunu ifade ettiler. Bunun nedeni olarak modelin klinikte kullanımının az olması ve dolayısıyla öğrencilerin yeterli deneyime sahip olmamaları düşünülmektedir.

Literatüre bakıldığında Kawa modeli'nin, bireylerin kendilerini ifade etmelerine ve aktivite profillerinin belirlenmesine yardımcı olduğu görülmektedir (Carmody ve ark, 2007). Bu bilgiler, kişi için anlamlı olanın anlaşılması ve terapiye aktif katıımın artırıması açısından önemlidir (Youngstrom, Brayman, Anthony ve ark, 2002). Çalışmamızda modelin bireyleri tanımayı, motivasyon, ilgi ve becerilerini analiz etmeyi kolaylaştırdığı, bunun sonucu olarak da kişinin tedavi sürecine aktif katılımının arttığı öğrenciler tarafından ifade edildi.

Multiple Sklerozlu bireylerde Kawa Modeli kullanımına ilişkin yapılan bir çalışmada bireylerin nehirlerini çizme konusunda tereddüt yaşadıkları ortaya konulmuştur. Terapistin görüşme becerilerinin, bireylerin kendi nehirlerini çizme ve metaforları doğru kullanma açısından çok önemli olduğu belirtilir. Terapist deneyim kazandıkça bireyleri çizim konusunda daha iyi yönlendireceğini ifade edilir (Carmody ve ark, 2007). Çalışmamızda katılımcıların \%50'si (10) bireylerin çizim aşamasında tereddüt yaşadıklarını ve bazı metaforları birbirinden ayırt etmede zorlandıklarını ifade etti. Katılımcılar bunu şu şekilde dile getirdi:

“Hasta 'benim resmim kötü o yüzden çizemem' diye bir tereddüt yaşadı. Ama ben kişiyi biraz daha cesaretlendirdiğimde çizmeyi kabul etti” (ET).

"Hasta çizim konusunda neyi nereye çizeceğini, ne kadar büyük olması gerektiğini organize etmekte zorlandı. Bu konuda daha fazla tecrübem olsaydı kişiyi daha kolay yönlendirebileceğimi düşünüyorum" $(A E)$.

Lakoff ve Johnson (1980) düşüncelerimizi kavramsallaştırmamızın yolunun büyük ölçüde metaforik bir süreç olduğu savunmaktadır. Dolayısıyla düşünce biçimimiz, deneyimlerimiz, ilişki kurma şekillerimiz ve günlük hayatımızda yaptığımız aktiviteler metafor kullanımıyla çok daha renklidir.

Paxson ve arkadaşları (2012) tarafından yapılan çalışmada metafor kullanımının açık ve evrensel bir dil olduğu vurgulanmaktadır. Aynı zamanda hastalar için ilgi çekici olduğu, hasta ve terapist arasındaki etkileşimi ve enerji seviyesini yükselttiği saptanmıştır. Çalışmamızda katılımcıların sadece $\% 15$ 'i (3) metafor kullanımını olumlu olarak nitelerken \%30'u (6) metafor kullanımında zorlandıklarını ifade etti. Bunun nedeni olarak yine öğrencilerin yeterli deneyime sahip olmadıklarını ve metafor kullanımına yabancı olduklarını düşünmekteyiz. Katılımcıların metafor kullanımına yönelik olumlu ifadeleri şu şekildedir:

"Kaya ve nehir gibi metaforları kullanmak hastamın modele karşı olan motivasyonunu artırdı". (GG)

"Hayatın akışını nehir olarak tanımlamak kişinin hoşuna gitti. Müziğe benzetti” (BY).

Öğrenciler çalışmaya katılmayı kabul etseler de modele karşı ilgisiz olmaları ve deneyimlerinin az olması, modelin klinikte kullanımının az olması çalışma için bir limitasyon oluşturmuştur.

Çalışmamız Kawa Modeli'nin kullanımının olumlu ve olumsuz özelliklerini ortaya koymaktadır. Olumsuz olarak görülen özelliklerin aslında öğrencilerin yeterli deneyime sahip olmamalarından kaynaklandığı düşünülmektedir. Bu nedenle modelin uygulama alanlarında kullanımının teşvik edilmesi önerilmektedir. Çalışmamızın modeli kullanmak isteyen kişiler için rehber olacağını düşünmekteyiz.

\section{Kaynaklar}

Ashby, S., \& Chandler, B. (2010). An exploratory study of the occupation-focused models included in occupational therapy professional education programmes. $\mathrm{Br} \mathrm{J}$ Occup Ther, 73(12), 616-624.

Batıhan, S., \& Kayıhan, H. (2016). Serebral palsili bir çocukta PEO temelli ergoterapi müdahale programının aktivite performansı ve yaşam kalitesine etkisi: Olgu çalışması. Ergoterapi ve Rehabilitasyon Dergisi, 4(1), 35-41.

Baum, C. M, \& Law, M. (1997). Occupational therapy practice: Focusing on occupational performance. Am J Occup Ther, 51(4), 277-288.

Carmody, S, Nolan, R, Ni Chonchuir, N, Curry, M, Halligan, C, \& Robinson, K. (2007). The guiding nature of the kawa (river) model in Ireland: creating both opportunities and challenges for occupational therapists. Occup Ther Int, 14(4), 221-236.

Davies, S. (2006). Models and theories. Reel K, \& Feaver S. (Eds.), Rehabilitation the Use of Theories and Models in Practice, (pp. 47-62). London: Elsevier.

Duncan, E. (2006). Foundations for Practice in Occupational Therapy (Fourth edition). London: Churchill Livingstone.

Gillen, A.,\& Greber, C. (2014). Occupation-focused practice: Challenges and choices. Br J Occup Ther, 77(1), 39-41.

Hammell, K. W. (2009). Sacred texts: A sceptical exploration of the assumptions underpinning theories of occupation. Can J Occup Ther, 76(1), 6-13.

Hocking, C., Pierce, D., Shordike, A., Wright-St. Clair, V., Bunrayong, W., Vittayakorn, S., \& Rattakorn, P. (2008). 
The promise of internationally collaborative research for studying occupation: The example of the older women's food preparation study. OTJR: Occupation, Participation and Health, 28(4), 180-190.

Hopkins, M. (2005). The relevance of culture to occupational therapy. Irish Journal of Occupational Therapy, 34(1), 22.

Iwama, M. (2003). Towards culturally relevant epistemologies in occupational therapy. Am J Occup Ther,57(5), 582-588.

Iwama, M. (2005b). The Kawa (River) Model; nature, life flow and the power of culturally relevant occupational therapy. Kronenberg, F, Algado, S. A, \& Pollard, M. (Eds.), Occupational Therapy Without Borders - Learning from the Spirit of Survivors, (pp. 213-227). Edinburgh: Churchill Livingstone.

Iwama M. (2006). The Kawa Model: Culturally Relevant Occupational Therapy. Edinburgh, UK: Churchill Livingstone Elsevier.

Iwama, M., Thomson, N., \& Macdonald, R. (2009). The Kawa model: The power of culturally responsive occupational therapy. Disabil Rehabil, 31(14), 1125-1135.

Kantartzis S, \& Molineux M. (2011). The influence of western society's construction of a healthy daily life on the conceptualization of occupation. Journal of Occupational Science, 18(1), 62-80.

Kashefimehr, B. (2014). Otizm spektrum bozukluğu olan çocuklarda Moho Modeline göre duyu algı bütünleme tedavisinin incelenmesi (Doktora Tezi). Hacettepe Üniversitesi Sağlık Bilimleri Enstitüsü, Ergoterapi Programı, Ankara.

Lakoff, G, \& Johnson, M. (2008). Metaphors we live by. University of Chicago press.

Lape, J. E., \& Scaife, B. D. (2017). Use of the KAWA Model for Teambuilding with Rehabilitative Professionals: An Exploratory Study. Internet Journal of Allied Health Sciences and Practice, 15(1), 10.

Nelson, A. (2007). Seeing white: a critical exploration of occupational therapy with Indigenous Australian people. Occup Ther Int, 14(4), 237-255.

Öz Z., \& Akı E. (2016). Parkinsonlu bireylerde müzik eşliğinde ritmik hareket tedavisinin günlük yaşam aktivitelerindeki bağımsızlık ve aktivite performansına etkisi. Ergoterapi ve Rehabilitasyon Dergisi, 4(1), 43-50.

Paxson, D, Winston, K, Tobey, T, Johnston, S., \& Iwama, M. (2012). The Kawa Model: therapists' experiences in mental health practice. Occupational Therapy in Mental Health, 28(4), 340-355.

Salar, S., Günal, A., Pekçetin, S., Huri, M., Mehr, B. K., Katırcıbaşı, G., \& Uyanık, M. (2016). Yaşlılarda aktivite, çevre ve yaşam memnuniyeti ilişkisi. Ergoterapi ve Rehabilitasyon Dergisi, 4(2), 89-96.

Salar, S. (2018). Şiddet görmüş kadınlarda ergoterapinin aktivite ve rol yeterliliğine etkisi. (Doktora Tezi). Hacettepe Üniversitesi Sağlık Bilimleri Enstitüsü, Ergoterapi Programı, Ankara.

Şen, E. B., \& Öksüz, Ç. (2016). Ankara'daki engelsiz parkların engelli çocukların kullanımına uygunluğunun değerlendirilmesi. Ergoterapi ve Rehabilitasyon Dergisi, 4(1), 15-25.

Tripathi, N. S., Sweetman, M. M., \& Zapf, S. A. (2017). Use of the Kawa Model for occupation-based culturally responsive occupational therapy in India. Indian Journal of Occupational Therapy, 49(4), 148-153.
Turpin, M., \& Nelson, A. (2007). The Kawa model: Culturally relevant occupational therapy. Aust Occup Ther J, 54(4), 323-324.

Youngstrom, M. J., Brayman, S. J, Anthony, P., Brinson, M., Brownrigg, S., Clark, G. F., \& et al. (2002). Occupational therapy practice Framework: Domain and process. Am J Occup Ther, 56, 609-639. 